\title{
Application of Six Sigma Methodology to Reduce Defects of a Grinding Process
}

\author{
E. V. Gijo ${ }^{a}$, Johny Scariab and Jiju Antony ${ }^{c * \dagger}$
}

\begin{abstract}
Six Sigma is a data-driven leadership approach using specific tools and methodologies that lead to fact-based decision making. This paper deals with the application of the Six Sigma methodology in reducing defects in a fine grinding process of an automotive company in India. The DMAIC (Define-Measure-Analyse-Improve-Control) approach has been followed here to solve the underlying problem of reducing process variation and improving the process yield. This paper explores how a manufacturing process can use a systematic methodology to move towards world-class quality level. The application of the Six Sigma methodology resulted in reduction of defects in the fine grinding process from 16.6 to $1.19 \%$. The DMAIC methodology has had a significant financial impact on the profitability of the company in terms of reduction in scrap cost, man-hour saving on rework and increased output. A saving of approximately US\$2.4 million per annum was reported from this project. Copyright $\odot 2011$ John Wiley \& Sons, Ltd.
\end{abstract}

Keywords: Six Sigma; Kappa statistic; process capability evaluation; chi-square test; ANOVA; Taguchi methods

\section{Introduction}

$\mathrm{S}$

ix Sigma is a well-structured methodology that focuses on reducing variation, measuring defects and improving the quality of products, processes and services. Six Sigma methodology was originally developed by Motorola in 1980s and it targeted a difficult goal of 3.4 parts per million defects ${ }^{1}$. Six Sigma has been on an incredible run over 25 years, producing significant savings to the bottom line of many large and small organizations ${ }^{2}$. Leading organizations with a track record in quality have adopted Six Sigma and claimed that it has transformed their organization ${ }^{3}$. Six Sigma was initially introduced in manufacturing processes; today, however, marketing, purchasing, billing, invoicing, insurance, human resource and customer call answering functions are also implementing the Six Sigma methodology with the aim of continuously reducing defects throughout the organization's processes ${ }^{4}$.

According to Harry and Schroeder ${ }^{5}$, Six Sigma is a powerful breakthrough business improvement strategy that enables companies to use simple and powerful statistical methods for achieving and sustaining operational excellence. It is a business strategy that allows companies to drastically improve their performance by designing and monitoring everyday business activities in ways that minimize waste and resources while increasing customer satisfaction ${ }^{6}$. The Six Sigma approach starts with a business strategy and ends with top-down implementation, having a significant impact on profit, if successfully deployed ${ }^{3}$. Numerous books and articles provide the basic concepts and benefits of the Six Sigma methodology. These publications cover topics, such as What is Six Sigma $^{3}$ ? Why do we need Six Sigma ${ }^{7}$ ? Six Sigma deployment ${ }^{8}$; critical success factors of the Six Sigma implementation ${ }^{4}$; Hurdles in the Six Sigma implementation ${ }^{9}$; the Six Sigma project selection ${ }^{10}$ and organizational infrastructure required for implementing Six Sigma ${ }^{11}$. Numerous articles are available in different aspects of Six Sigma over the past 10 years ${ }^{12-17}$. The Six Sigma approach has been widely used to improve performances and reduce costs for several industrial fields ${ }^{18-22}$.

This paper presents the step-by-step application of the Six Sigma DMAIC (Define-Measure-Analyse-Improve-control) approach to eliminate the defects in a fine grinding process of an automotive company. This has helped to reduce defects in the process and thereby improve productivity and on time delivery to customer. During the measure and analyse phases of the project, data were collected from the processes to understand the baseline performance and for validation of causes. These data were studied through various graphical and statistical analyses. Chi-square test, ANOVA ${ }^{23}$, Design of Experiments (DOE) ${ }^{24}$, Control Charts ${ }^{25}$, Taguchi methods 26 , etc. were used to make meaningful and scientifically proven conclusions about the process and the related causes.

\footnotetext{
aSQC \& OR Unit, Indian Statistical Institute, 8th Mile, Mysore Road, Bangalore 560 059, India

${ }^{b}$ Department of Statistics, Nirmala College, Muvattupuzha 686 661, India

'Department of DMEM, University of Strathclyde, Glasgow, Scotland G1 1XJ, U.K.

*Correspondence to: Jiju Antony, Department of DMEM, University of Strathclyde, Glasgow, Scotland G1 1XJ, U.K.

${ }^{\dagger}$ E-mail: jiju.antony@strath.ac.uk
} 
The structure of this article is as follows. The research methodology adopted for this study is explained in Section 2 . Section 3 explains an introduction to the case study, Section 3.1 indicates the define phase, Section 3.2 details the measure phase with baseline performance. The Analyse phase is explained in Section 3.3 with details of potential causes and its validation followed by the Improvement phase in Section 3.4 with details of solutions implemented. Section 3.5 explains the controls introduced to ensure sustainability of the results. Section 4 provides information about the lessons learned followed by Section 5 , the managerial implications of the initiative. Section 6 presents the concluding remarks and discusses the benefits and limitations of the study.

\section{Research methodology}

This section explains the methodology adopted for this case study. Scientific investigation on innovating a system or improvement to the existing one needs to begin with some structure and plan. This structure and plan of investigation were conceived so as to obtain answers to research questions in the research design ${ }^{27}$. The researcher worked with the company to provide support for the project in the Six Sigma techniques, whilst recording data about the exercise from which to develop a case study. A literature review was undertaken with an objective of identifying the past history of various improvement initiatives carried out to address process-related problems.

The methodology is divided into four major sections namely problem definition, literature survey, case study design and data analysis. Based on the available data on the process, the team studied the baseline status of the process and drafted a project charter, which explains the details of the problem. A detailed literature review was undertaken in Six Sigma with an objective of identifying the type of improvements carried out by different people in various organizations to address process-related problems.

A case study entails the detailed and intensive analysis of a single case-a single organization, a single location or a single event $^{28}$. Yin ${ }^{29}$ describes a case study as an empirical inquiry that investigates a contemporary phenomenon within its reallife context. According to Lee ${ }^{30}$, the unit of analysis in a case study is the phenomenon under study and deciding this unit appropriately is central to a research study. In this paper, a case study is designed to study the underlying process problem so that solutions can be implemented for process improvement. The collected data were analysed using descriptive and inferential statistics. Measurement system analysis, chi-square test, ANOVA, DOE with Taguchi methods, etc. were used for analysing the data and inferences were made. Graphical analyses, such as histogram and control chart, were also utilized for summarizing the data and making meaningful conclusions. Minitab statistical software was used to analyse the data collected at different stages in the case study.

\section{Case study}

This case study deals with the reduction of defects in the fine grinding process in an automobile part manufacturing company in India. The company with manpower of approximately 2550 people is manufacturing common rail direct injection (CRDI) system pumps for vehicles. These pumps were used in cars, trucks and buses throughout the world. An injector primarily consists of nozzle and nozzle holder body. A schematic view of fuel injector is given in Figure 1. The components used in fuel injector and
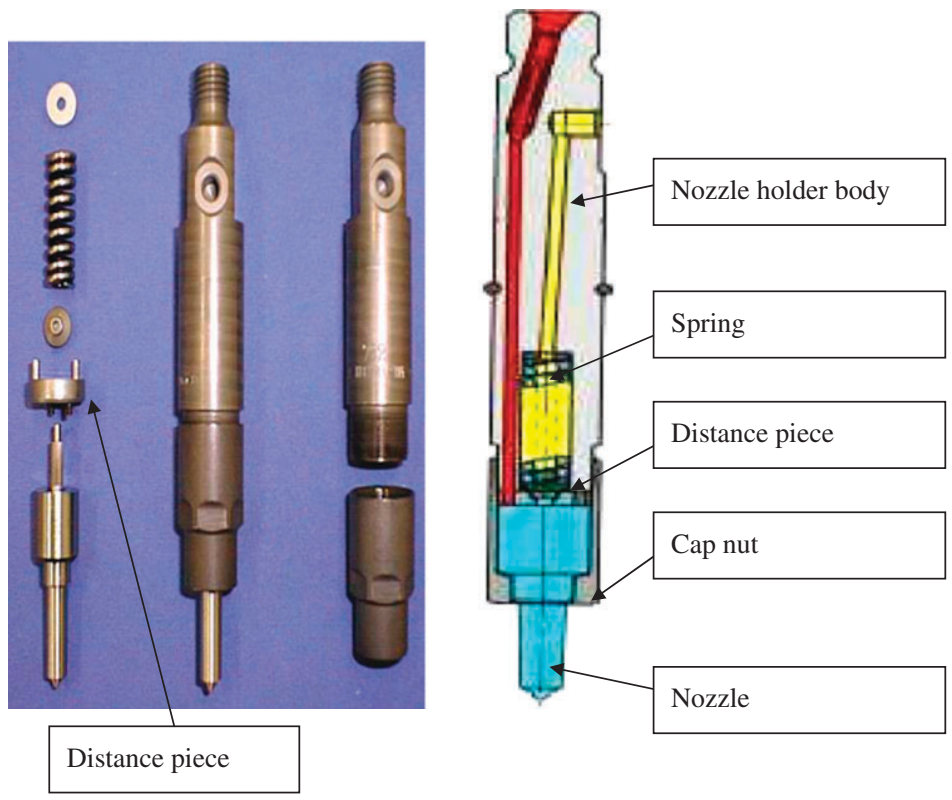

Figure 1. Schematic view of fuel injector 
their functions are as follows. Distance piece aligns the high-pressure fuel lines of nozzle holder body and nozzle. Its both sides are fine ground precisely to ensure sealing of the high-pressure fuel coming from holder body to nozzle. Cap nut retains the nozzle and distance piece with the holder body with sufficient torque to ensure sealing. Spring and pressure bolt ensures the functioning of injector with set opening pressure and timely delivery of fuel.

The current project was undertaken in the distance piece fine grinding process, which is done by fine grinding machine. Different types of distance pieces were fine ground in this machine. This is a sophisticated and very expensive CNC fine grinding machine. It finishes both faces of distance pieces in batches precisely with sub-micron flatness values.

After fine grinding, distance pieces were inspected visually to find various defects. Since the production of distance pieces were in thousands per shift, it was not practically possible to do $100 \%$ inspection of these components by objective methods. Hence visual inspection was carried out for all the components with reference to master pieces and visual limit samples. Since the rejection level of distance pieces after fine grinding process was very high and the function of the component in the product was highly critical, it was essential to do $100 \%$ inspection. Under these circumstances, the project was of highest priority to the management as it was clear that an effective solution to this problem would have a significant impact in reducing rework/ rejection and improving productivity. Also, it was clear to the team members and champion of the project that the elimination of this problem will help the organization to cater to the increasing demand of market. In the past, many attempts were made to solve this problem by using different methodologies, which were unsuccessful. The Six Sigma problem solving methodology (DMAIC) was recommended when the cause of the problem is unclear ${ }^{3}$. Hence, it was decided to address this problem through the Six Sigma DMAIC methodology.

\subsection{Define phase}

This phase of the DMAIC methodology aims to define the scope and goals of the improvement project in terms of customer requirements and to develop a process that delivers these requirements. The first step towards solving any problem in the Six Sigma methodology is by formulating a team of people associated with the process. The team selected for this project includes the Senior Manager-Manufacturing as the Black Belt (BB). The other members of the team were Planning Manager, Maintenance Manager, Quality Control Senior Engineer and one Machine Operator. BB acts as the team leader, and was responsible for the overall success of the project. In this particular project, BB himself was the process owner. The primary responsibility of team members was to support BB in executing the project-related actions. The Head of manufacturing department was identified as the Champion and the Head of Business Excellence department as master black belt (MBB) for this project. The team along with the Champion and MBB developed a project charter (Appendix 1) with all necessary details of the project. This has helped the team members to clearly understand the project objective, project duration, resources available, roles and responsibilities of team members, project scope and boundaries, expected results from the project, etc. This creates a common vision and sense of ownership for the project, so that the entire team is focused on the objectives of the project.

The team had several meetings with the Champion and MBB to discuss various aspects of the problem, including the internal and customer-related issues arising because of this problem. The team decided to consider the rejection percentage of distance pieces after fine grinding process as the Critical to Quality (CTQ) characteristic for this project. The goal statement was defined as the reduction in rejection of distance pieces by $50 \%$ from the existing level, which should result in large cost saving for the company in terms of reduction in rework and scrap cost.

Since there was a cross-functional team for executing this project, the team felt that it was necessary to perform a SIPOC (Supplier-Input-Process-Output-Customer) analysis to have a better understanding of the process. This is a method similar to process mapping for defining and understanding process steps, process inputs and process outputs ${ }^{3}$. The team with the involvement of people working with the process prepared a SIPOC mapping along with a basic flowchart of the process. This SIPOC has given a clear understanding of the process steps needed to create the output of the process. Through this exercise, the team got the clarity of the project in terms of the scope of the project, inputs, outputs, suppliers and customers of the process. The team focused on the fine grinding process for improvement that is defined as the scope of the project. The process mapping along with SIPOC is presented in Appendix 2.

\subsection{Measure phase}

The objective of the measure phase is to understand and establish the baseline performance of the process in terms of process capability or sigma rating. The CTQ considered in this case was the rejection percentage of distance pieces after the fine grinding process. These rejections were mainly due to the occurrence of different types of defects, such as burr, shades, deep lines, patches and damage, on the component after machining. The schematic representation of these defects is presented in Figure 2. These defects create an uneven surface in the component that could lead to fuel leakages in pumps. After machining, the components were visually inspected for these defects. Master samples were provided for identifying each of these defects and inspectors did the inspection. Since there was no instrument involved in the inspection process and only visual inspection was performed, before going ahead with further data collection, the team decided to carry out Attribute Gage Repeatability and Reproducibility (Gage R \& R) study to validate the measurement system. In such studies, intra-inspector agreement measures repeatability (within inspector), inter inspector agreement measures the combination of repeatability and reproducibility (between inspectors) ${ }^{31}$. The non-chance agreement between the two inspectors, denoted by Kappa, defines as

$$
\kappa=\frac{\text { Number of observed agreements-Number of expected agreements }}{\text { Total number of observations }- \text { Number of expected agreements }} \text {. }
$$




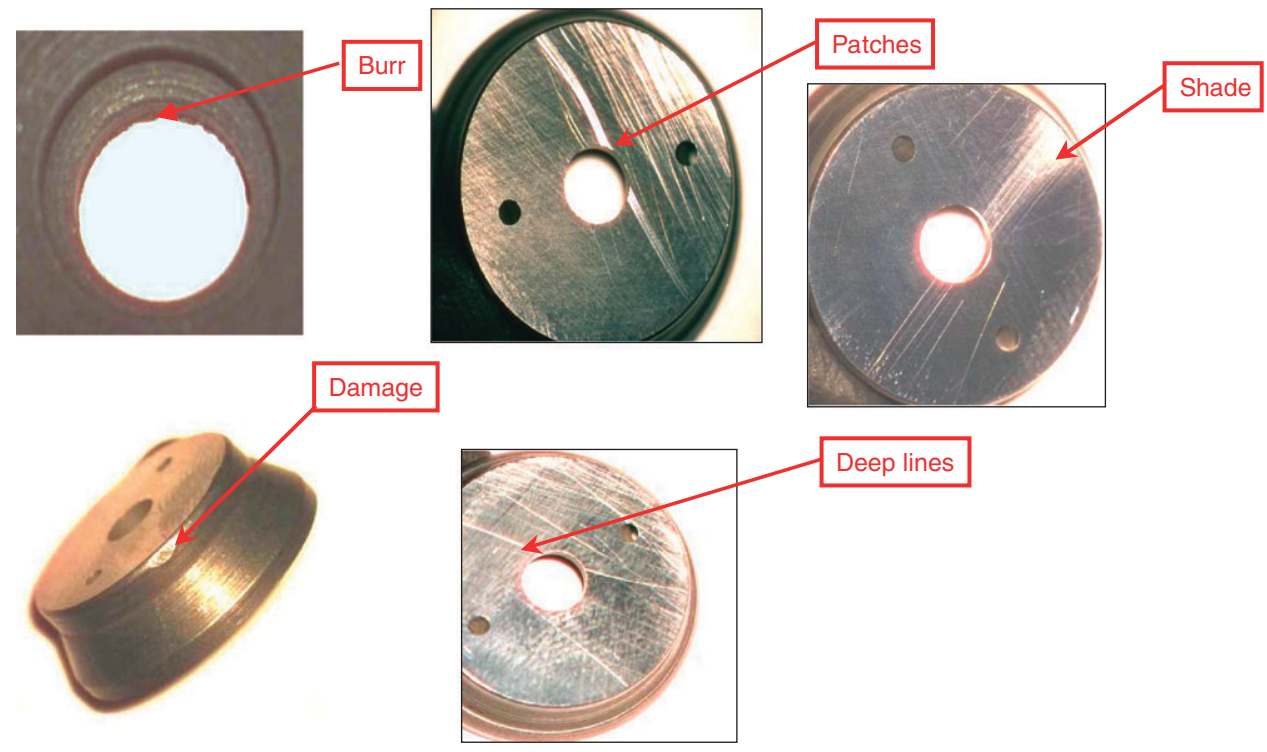

Figure 2. Schematic representation of defects

\begin{tabular}{|lcccc|}
\hline \multicolumn{2}{|c|}{ Table I. Data collection plan } & & & \\
Characteristic & Data type & How measured & Sampling notes & Related conditions \\
\hline $\begin{array}{l}\text { Rejection percentage of } \\
\text { distance pieces after the } \\
\text { fine grinding process }\end{array}$ & Attribute & $\begin{array}{l}\text { Visual checking by comparing } \\
\text { with visual limit samples }\end{array}$ & $\begin{array}{l}100 \% \text { of units in all the } \\
\text { three shifts for two months }\end{array}$ & $\begin{array}{l}\text { Shift wise and defect } \\
\text { type wise }\end{array}$ \\
\hline
\end{tabular}

For conducting the study, 100 components were selected and they were classified as good or bad independently by two inspectors. From the resulting data, the Kappa value was calculated and was found to be 0.814 with a standard error of 0.0839 . Since the Kappa value was more than 0.6 , the measurement system was acceptable ${ }^{31}$.

After the measurement system study, a data collection plan was prepared with details of types of data, stratification factors, sampling frequency, method of measurement, etc. for the data to be collected during the measure phase of this study. The data collection plan thus prepared is presented in Table I. The data were collected as per the plan to understand the baseline status of the process. During the defined period of data collection, 368219 components were inspected and 61198 components were rejected due to various defects. Each one of the rejected components was having one or more defects. The detailed data on the type of defects were collected and the same was graphically presented as a pareto diagram (Figure 3). The collected data shows that the rejection in the process was 166200 PPM. The corresponding sigma rating of the process can be approximated to 2.47 .

For any improvement initiative in this organization, the general goal set by the management was to reduce the rejection by $50 \%$ from the existing level. Based on this policy, the target set for the study was to reduce the rejections at the fine grinding process to 83100 PPM from the existing level of 166200 PPM.

\subsection{Analyse phase}

After mapping the process, the team proceeded to analyse the potential causes of defects. A cause and effect diagram was prepared after conducting a brain storming session with all the concerned people from the process along with the project team, Champion and MBB. The output of the cause and effect diagram depends on a large extent on the quality and creativity of the brain storming session ${ }^{32}$. Figure 4 illustrates the cause and effect analysis prepared during the brain storming session.

The next step in this phase was to gather data from the process in order to obtain a better picture of the potential causes, so that the root cause/s can be identified. The team had detailed discussion with the process personnel to identify the possible data that can be collected on the potential causes in the cause and effect diagram. After getting the detailed picture of availability of data on causes, the team discussed with MBB to identify the type of analysis possible on these causes. Based on this discussion, a cause validation plan was prepared to detail the type of data to be collected and the type of analysis possible for each of these causes. The potential causes, such as 'variation in input parts', 'supplier material variation' and 'program parameters not OK', can be validated by statistical analysis on the data collected from the process. But potential causes, such as 'improper cleaning after dressing' and 'repair batches mix up', have to be validated only by observing the process (gemba). Hence for few causes, detailed data were collected and statistical analyses were planned, and for the remaining causes gemba was planned to validate the causes. Table II summarizes the potential causes and the type of analysis planned for each cause. 


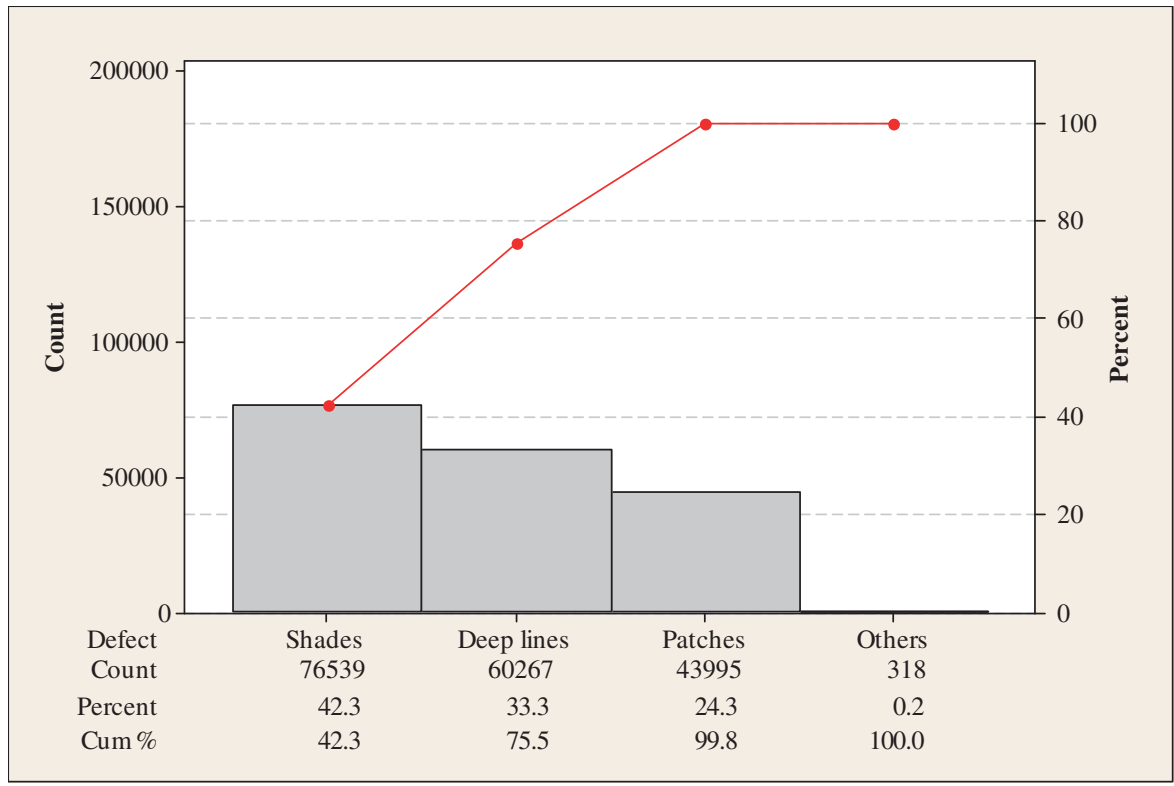

Figure 3. Pareto diagram for visual defects

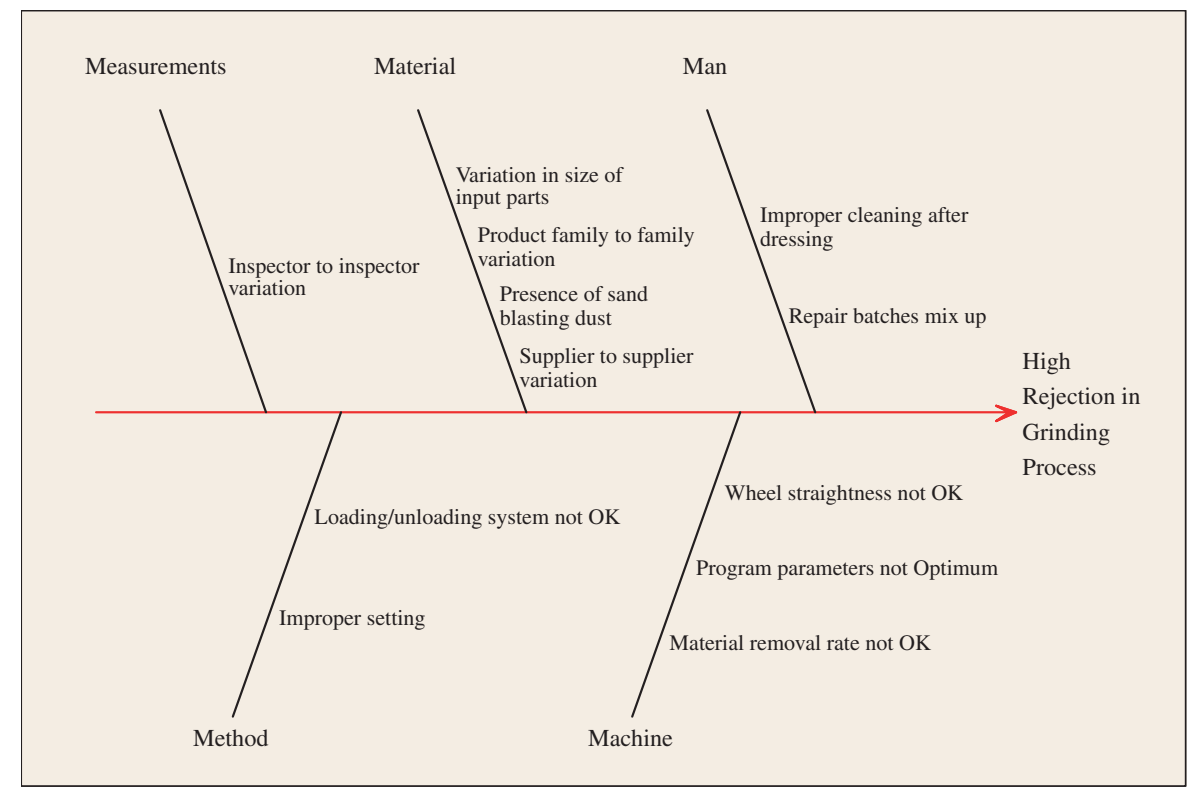

Figure 4. Cause and effect diagram for rejection in grinding process

As three different suppliers provided the raw material, it was suspected that there was possibility of supplier-to-supplier variation with respect to the thickness of input raw material. To study this variation, the data on the thickness of components from all the three suppliers were collected and ANOVA (A statistical procedure used to determine the significant effect of a variable under study ${ }^{23}$.) was performed in the data and $p$-value was observed. $P$-value is a means for judging the significance of a statistical test. The smaller the $p$-value, the more significant the results are. Typically values below 0.05 are considered indicative of a significant test outcome 25 . In this case, $p$-value was found to be 0.407 , ruling out the possibility of significant difference between the suppliers ${ }^{23}$. Further to validate the potential cause of variation in size of input parts, a batch of 57 distance pieces were selected and thickness measured. The data were subjected to Anderson Darling Normality test, and found to follow normal distribution ${ }^{23}$. Process capability study was carried out on this data and found to be capable, confirming that the thickness variation in input part was not a root cause ${ }^{33}$. The Process capability study is a comparison of the process output with customer requirements to determine whether a process is capable of meeting customer expectations ${ }^{25}$. The Minitab statistical software output of process capability evaluation is presented in Figure 5. 


\begin{tabular}{|lrc|}
\hline \multicolumn{2}{|c|}{ Table II. Cause validation plan } \\
SI. no & Cause & Plan for validation \\
\hline 1 & Improper cleaning after dressing & GEMBA \\
2 & Repair batches mix up & GEMBA \\
3 & Variation in size of input parts & Process capability analysis \\
4 & Product family to family variation & Chi-square test \\
5 & Presence of sand blasting dust & GEMBA \\
6 & Supplier to supplier variation & ANOVA \\
7 & Material removal rate not OK & ANOVA \\
8 & Process parameters not Optimum & Design of experiments (DOE) \\
9 & Improper setting & DOE \\
10 & Loading/unloading system not OK & GEMBA \\
11 & Wheel straightness not OK & GEMBA \\
12 & Inspector to inspector variation & Gauge R \& R \\
\hline
\end{tabular}

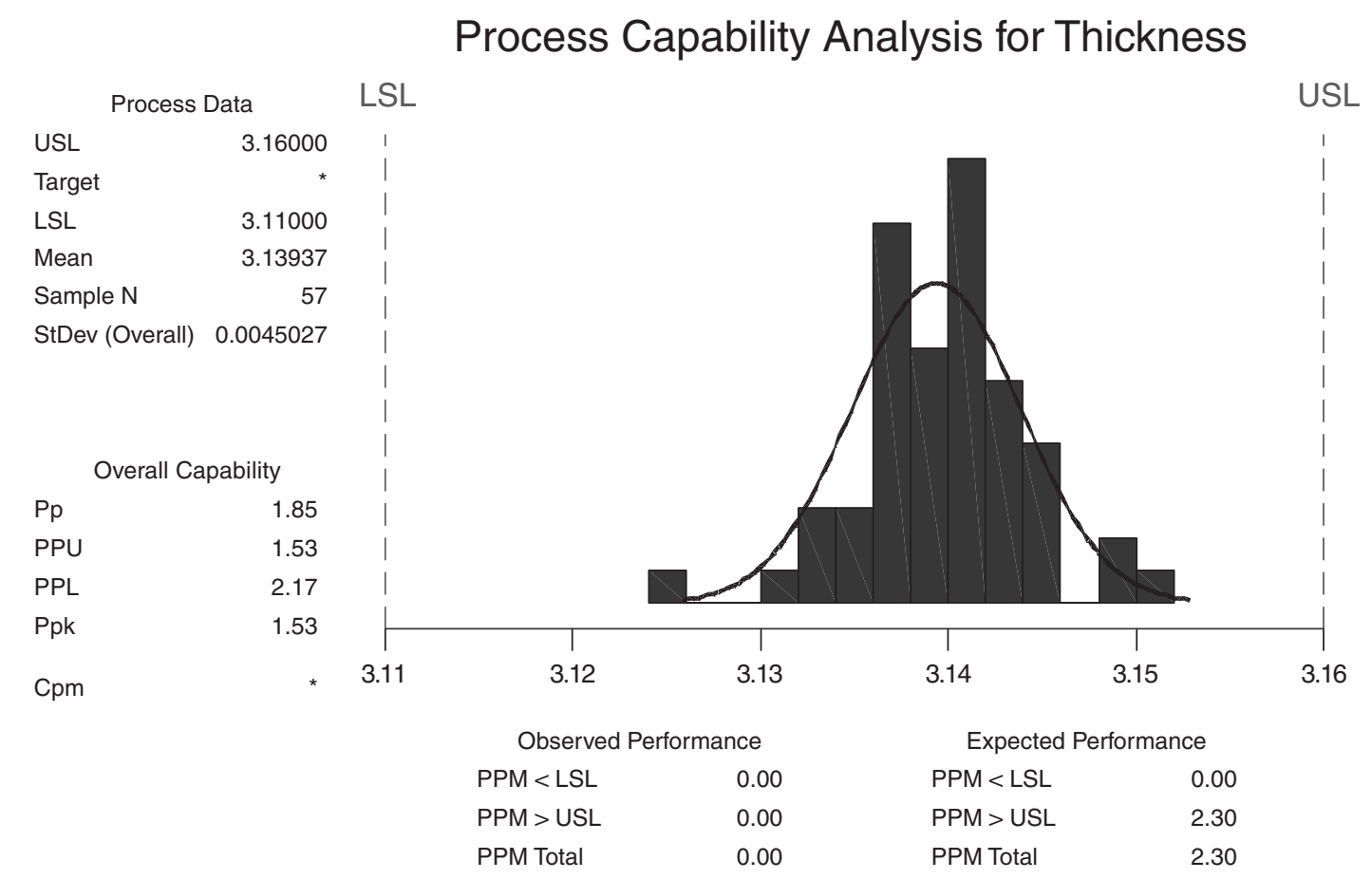

Figure 5. Process capability analysis

Since different families of products were produced, data were collected for material removal rate (MRR) as well as defects with respect to various families of components to test their significance. Data on MRR were collected on three types of components to study the effect of type of component on MRR. Based on the quantity of material removed from the component during machining, the MRR value was calculated by an inbuilt software program in the machine. These MRR data were recorded in millimeter/minute. ANOVA was performed on this data and $p$-value was found to be 0.085 , not showing significance at $5 \%$ level 23 . To test whether product family-to-family variation affects the defects, a chi-square test was carried out between defect type and family of components ${ }^{23}$. For each of the defect types, viz., patches, shades and deep lines, separate chi-square test was done with three different families of components. The details of chi-square test are given in Table III. From Table III, it was clear that except for shades, family-to-family variation does not affect visual defects. The machining program and machine parameters for each family and type were different. The team thought, it was better to have a uniform machining program and parameters for all the family components so that the process can be better managed. Hence for validating the process parameters and identifying the optimum operating conditions, the team decided to conduct a DOE during the improve phase. DOE is a technique for understanding variability, in which factors are systematically and simultaneously manipulated while the variability in outputs (responses) is studied to determine which factors have the biggest impact ${ }^{24}$.

The other causes listed in the cause and effect diagram were validated by gemba analysis. Some of the details are presented in Table IV. The details of validation of all causes in the cause and effect diagram are summarized in a tabular format and is given in Table $\mathrm{V}$. 


\begin{tabular}{|lccr|}
\hline \multicolumn{4}{|c|}{ Table III. Test statistic values for Chi-square test } \\
Defect type & Chi-square statistic & Degrees of freedom & $p$-value \\
\hline Patches & 2.509 & 2 & 0.285 \\
Deep lines & 2.398 & 2 & 0.301 \\
Shades & 452.256 & 2 & 0.000 \\
\hline
\end{tabular}

\begin{tabular}{|c|c|c|}
\hline SI. no. & Cause & Observation/conclusion \\
\hline 1 & Improper cleaning after dressing & It was observed that cleaning done after dressing. Not a root cause. \\
\hline 2 & Repair batches mix up & $\begin{array}{l}\text { Repair batches were found mixed with other batches during the random visit to } \\
\text { the process. Root cause. }\end{array}$ \\
\hline 3 & Presence of sand blasting dust & $\begin{array}{l}\text { Traces of shot blasting dust found in the input batch during inspection. Root } \\
\text { cause. }\end{array}$ \\
\hline 4 & Loading/unloading system not OK & Loading table wear out observed at the edges. Root cause. \\
\hline 5 & Wheel straightness not OK & $\begin{array}{l}\text { Wheel straightness found OK. Checking frequency followed as per procedure. } \\
\text { Not a root cause. }\end{array}$ \\
\hline
\end{tabular}

\begin{tabular}{|lccc|}
\hline \multicolumn{2}{|c}{ Table V. Summary of validation of causes } & & \\
SI. no. & Cause & Tools used for validation & Results \\
\hline 1 & Improper cleaning after dressing & GEMBA & Not a root cause \\
2 & Repair batches mix up & GEMBA & Root cause \\
3 & Variation in size of input parts & Process capability analysis & Not a root cause \\
4 & Product family to family variation & Chi-square test & Root cause \\
5 & Presence of sand blasting dust & GEMBA & Root cause \\
6 & Supplier to supplier variation & ANOVA & Not a root cause \\
7 & Material removal rate not OK & ANOVA & Root cause \\
8 & Process parameters not optimum & DOE & Root cause \\
9 & Improper setting & DOE & Root cause \\
10 & Loading/unloading system not OK & GEMBA & Root cause \\
11 & Wheel straightness not OK & GEMBA & Not a root cause \\
12 & Inspector to inspector variation & Gauge R \& R & Not a root cause \\
\hline
\end{tabular}

\subsection{Improve phase}

This phase of the Six Sigma project is aimed at identifying solutions for all the root causes identified during the Analyse phase, implementing them after studying the risk involved in implementation and observing the results.

At this stage, as decided earlier, a DOE was planned for optimizing the process/machine parameters. The team along with champion, MBB, the production supervisor and operators of the process conducted a series of brain storming sessions to identify the important parameters for experimentation. The parameters selected through these discussions were load applied, initial load setting, coolant flow rate, upper wheel rpm, lower wheel rpm and cage rpm. Since the relationship between these parameters and MRR was not known, it was decided to experiment all these parameters at three levels ${ }^{26}$. The existing operating level was selected as one level for experimentation. The team based on various operational feasibilities selected the other two levels. The parameters and levels selected for experimentation are presented in Table VI. Also, the team felt there is a possibility of interaction between load applied with upper wheel rpm, load applied with lower wheel rpm and load applied with cage rpm. Hence it was decided to estimate the effect of these three interactions also. Six parameters at three levels and three interactions with replications require a huge number of components for conducting a full factorial experiment, which would be a costly and time-consuming exercise 24 . It was possible to estimate the effect of these selected parameters and interactions using the 27 experiments with the help of Orthogonal Array (OA). Hence for conducting an experiment with six parameters and three interactions, $L_{27}\left(3^{13}\right)$ orthogonal array was selected ${ }^{34}$. As the name suggests, the columns of this array are mutually orthogonal. Also, experiments using orthogonal arrays play a crucial role in achieving additivity of the model effects ${ }^{34}$. The design layout prepared as per $L_{27}\left(3^{13}\right)$ orthogonal array is given in Table VII. The response of the experiment was decided as material removal rate (MRR).

As per the design layout given in Table VII, the experiments were conducted after randomizing the sequence of experiments, and the data were collected ${ }^{32}$. The experimental data were analysed by Taguchi's Signal-to-Noise (S/N) ratio method ${ }^{35}$. The $S / N$ ratio is advocated in the Taguchi method to maximize the performance of a system or product by minimizing the effect of noise ${ }^{36}$. The $\mathrm{S} / \mathrm{N}$ ratio can be treated as a response (output) of the experiment, which is a measure of variation when uncontrolled 


\begin{tabular}{|lcccc|}
\hline \multicolumn{4}{|l}{ Table VI. Process parameters and their levels } \\
SI. no. & Factor & Levels & \\
\hline 1 & Load applied & 170 & $200^{*}$ & 230 \\
2 & Initial load setting & Minimum & Medium & Maximum \\
3 & Coolant flow rate & 8 LPM & 12 LPM & 16 LPM $^{*}$ \\
4 & Upper wheel RPM & $70^{*}$ & 90 & 110 \\
5 & Lower wheel RPM & $50^{*}$ & 60 & 70 \\
6 & Cage RPM & $20^{*}$ & 30 & 40 \\
\hline
\end{tabular}

*Existing levels.

\begin{tabular}{|c|c|c|c|c|c|c|}
\hline Exp. no. & Load & Setting & Coolant & UW RPM & LW RPM & C RPM \\
\hline 1 & 170 & Min. & 8 LPM & 70 & 50 & 20 \\
\hline 2 & 170 & Min. & 8 LPM & 90 & 60 & 30 \\
\hline 3 & 170 & Min. & 8 LPM & 110 & 70 & 40 \\
\hline 4 & 170 & Med. & 12 LPM & 70 & 60 & 40 \\
\hline 5 & 170 & Med. & 12 LPM & 90 & 70 & 20 \\
\hline 6 & 170 & Med. & 12 LPM & 110 & 50 & 30 \\
\hline 7 & 170 & Max. & 16 LPM & 70 & 70 & 30 \\
\hline 8 & 170 & Max. & 16 LPM & 90 & 50 & 40 \\
\hline 9 & 170 & Max. & 16 LPM & 110 & 60 & 20 \\
\hline 10 & 200 & Med. & 16 LPM & 70 & 50 & 20 \\
\hline 11 & 200 & Med. & 16 LPM & 90 & 60 & 30 \\
\hline 12 & 200 & Med. & 16 LPM & 110 & 70 & 40 \\
\hline 13 & 200 & Max. & 8 LPM & 70 & 60 & 40 \\
\hline 14 & 200 & Max. & 8 LPM & 90 & 70 & 20 \\
\hline 15 & 200 & Max. & 8 LPM & 110 & 50 & 30 \\
\hline 16 & 200 & Min. & 12 LPM & 70 & 70 & 30 \\
\hline 17 & 200 & Min. & 12 LPM & 90 & 50 & 40 \\
\hline 18 & 200 & Min. & 12 LPM & 110 & 60 & 20 \\
\hline 19 & 230 & Max. & 12 LPM & 70 & 50 & 20 \\
\hline 20 & 230 & Max. & 12 LPM & 90 & 60 & 30 \\
\hline 21 & 230 & Max. & 12 LPM & 110 & 70 & 40 \\
\hline 22 & 230 & Min. & 16 LPM & 70 & 60 & 40 \\
\hline 23 & 230 & Min. & 16 LPM & 90 & 70 & 20 \\
\hline 24 & 230 & Min. & 16 LPM & 110 & 50 & 30 \\
\hline 25 & 230 & Med. & 8 LPM & 70 & 70 & 30 \\
\hline 26 & 230 & Med. & 8 LPM & 90 & 50 & 40 \\
\hline 27 & 230 & Med. & 8 LPM & 110 & 60 & 20 \\
\hline
\end{tabular}

noise factors are present in the system ${ }^{34}$. Since the requirement of this process was to remove materials in a uniform rate from distance pieces to achieve specified dimension, the $S / N$ ratio of nominal-the-best type was selected for analysis ${ }^{36}$. The $S / N$ ratio for nominal the best type characteristic was defined as $10 * \log \left(\left(\bar{Y}^{2}\right) / s^{2}\right)$, where $\bar{Y}$ is the average and $s$, the standard deviation for each experiment ${ }^{26}$. The $\mathrm{S} / \mathrm{N}$ ratio values were estimated for all the 27 experiments and ANOVA was performed on these $\mathrm{S} / \mathrm{N}$ values to identify the significant parameters and interactions. From the ANOVA table (Table VIII), it was clear that the interaction effect between load applied and upper wheel rpm was significant at 5\% level of significance. Also, parameters setting and lower wheel rpm were significant at $10 \%$ level of significance. The main effect (the change in average response produced by a change in the level of the factor ${ }^{24}$ ) and interaction (a measure of the degree to which the effect on the response of one factor is dependent upon the settings of one or more other factors ${ }^{24}$ ) plots of the $\mathrm{S} / \mathrm{N}$ ratio values were made with the help of Minitab statistical software and are presented in Figures 6 and 7. From these plots, the best levels for parameters were identified as the level corresponding to highest value of $S / N$ ratio ${ }^{35}$. Thus, the best levels for load applied and upper wheel rpm were selected from the interaction plot and the best levels for the other parameters were selected from the main effect plot. The optimum combination for process parameters thus arrived at is given in Table IX. One important point to be noted here is that for the factor load applied, the best level from the main effect plot was $230 \mathrm{daN}$ and that from the interaction plot was 170 daN. This shows the importance of estimating interaction effect during the DOE study. 


\begin{tabular}{|lcccccr|}
\hline \multicolumn{7}{|l}{ Table VIII. ANOVA } \\
Source & DF & Seq. SS & Adj. SS & Adj. MS & $F$ & $p$-value \\
\hline Load & 2 & 0.0031630 & 0.0031630 & 0.0015815 & 07.00 & 0.125 \\
Setting & 2 & 0.0073185 & 0.0073185 & 0.0036593 & 16.20 & 0.058 \\
Coolant & 2 & 0.0020963 & 0.0020963 & 0.0010481 & 04.64 & 0.177 \\
UW RPM & 2 & 0.0005852 & 0.0005852 & 0.0002926 & 01.30 & 0.436 \\
LW RPM & 2 & 0.0050296 & 0.0050296 & 0.0025148 & 11.13 & 0.082 \\
C RPM & 2 & 0.0018296 & 0.0018296 & 0.0009148 & 04.05 & 0.198 \\
Load*UW RPM & 4 & 0.0198815 & 0.0198815 & 0.0049704 & 22.00 & 0.044 \\
Load*LW RPM & 4 & 0.0057037 & 0.0057037 & 0.0014259 & 06.31 & 0.141 \\
Load*C RPM & 4 & 0.0062370 & 0.0062370 & 0.0015593 & 06.90 & 0.131 \\
Error & 2 & 0.0004519 & 0.0004519 & 0.0002259 & & \\
Total & 26 & 0.0522963 & & & & \\
\hline
\end{tabular}

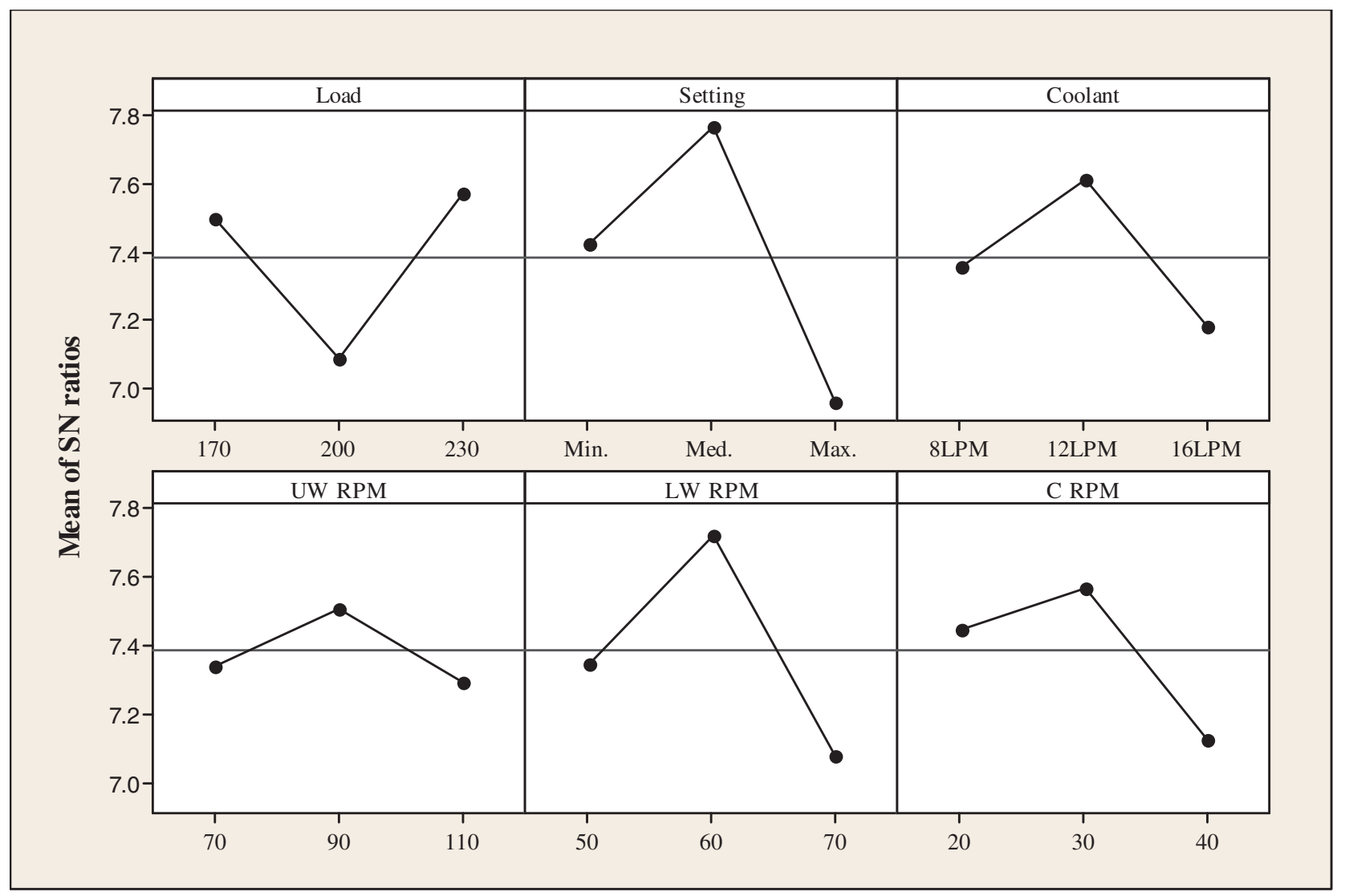

Figure 6. Main effects plot (data means) for $\mathrm{S} / \mathrm{N}$ ratios

These optimum levels in Table IX were taken as solutions for the causes related to process parameters. Finally, the list of selected solutions is presented in Table X. A risk analysis was carried out to identify any possible negative side effects of the solutions during implementation. The team concluded from the risk analysis that there were no significant negative impacts associated with any of the selected solutions. Hence, an implementation plan was prepared for the above solutions with responsibility and target date for completion for each solution. A time frame of two weeks was provided for implementing these solutions. All the solutions were implemented as per the plan and the results were observed. A graphical presentation of the comparison of results before and after the project is provided in Figure 8.

\subsection{Control phase}

The real challenge of the Six Sigma implementation is the sustainability of the achieved results. Due to variety of reasons, such as people changing the job, promotion/ transfer of persons working on the process, changing focus of the individual to other process-related issues elsewhere in the organization and lack of ownership of new people in the process, quite often maintaining 


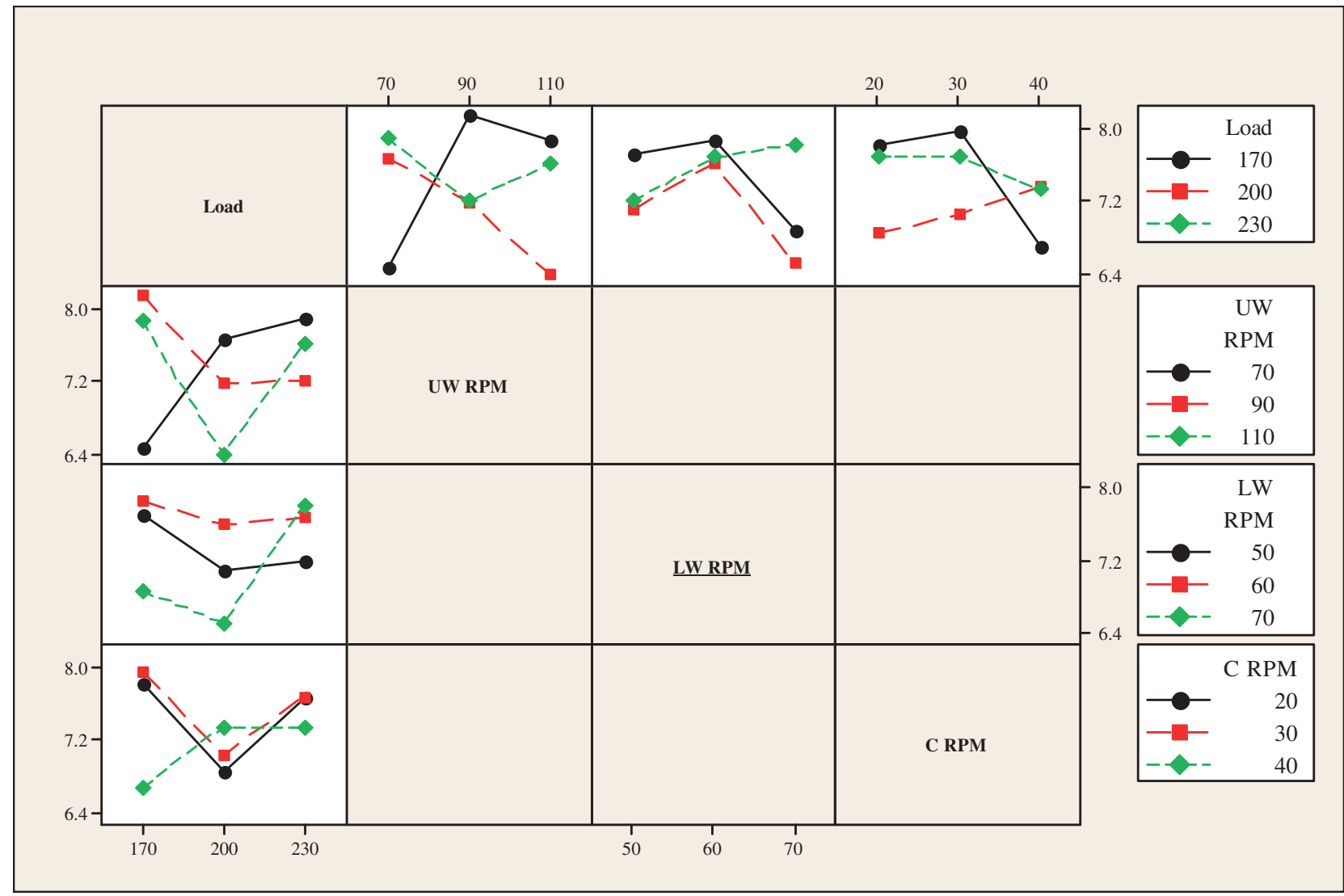

Figure 7. Interaction plot (data means) for $\mathrm{S} / \mathrm{N}$ ratios

\begin{tabular}{|lcc|}
\hline \multicolumn{2}{|c|}{ Table IX. Optimum combination for process parameters } \\
SI. no. & Factor & Optimum level \\
\hline 1 & Load applied & 170 \\
2 & Initial load setting & Medium \\
3 & Coolant flow rate & 12 \\
4 & Upper wheel RPM & 90 \\
5 & Lower wheel RPM & 60 \\
6 & Cage RPM & 30 \\
\hline
\end{tabular}

Table X. Cause-Solution matrix

\begin{tabular}{|lll|} 
SI. no. & \multicolumn{1}{c}{ Cause } & \multicolumn{1}{c}{ Solution } \\
\hline 1 & \multicolumn{1}{c}{ Repair batches mix up } & New storage system for repair parts introduced in the process \\
2 & Product family to family variation & Process parameters were optimized as per result of DOE \\
3 & Presence of sand blasting dust & Cleaning method after sand blasting introduced \\
4 & Material removal rate not OK & Reference table prepared for adjusting load \\
5 & Process parameters not OK & Optimum factor level combination from DOE \\
6 & Improper setting & Optimum factor level combination from DOE \\
7 & Loading/unloading system not OK & Conditioning of grinding wheel-loading table is done.
\end{tabular}

the results are extremely difficult ${ }^{9}$. Sustainability of the results requires standardization of the improved methods and introduction of monitoring mechanisms for the key results achieved. It also requires bringing awareness among the personnel performing the activities.

Standardization of the solutions was ensured by affecting necessary changes in the process procedures that was a part of the quality management system of the organization. The quality plans and control plans were revised as per the solutions 


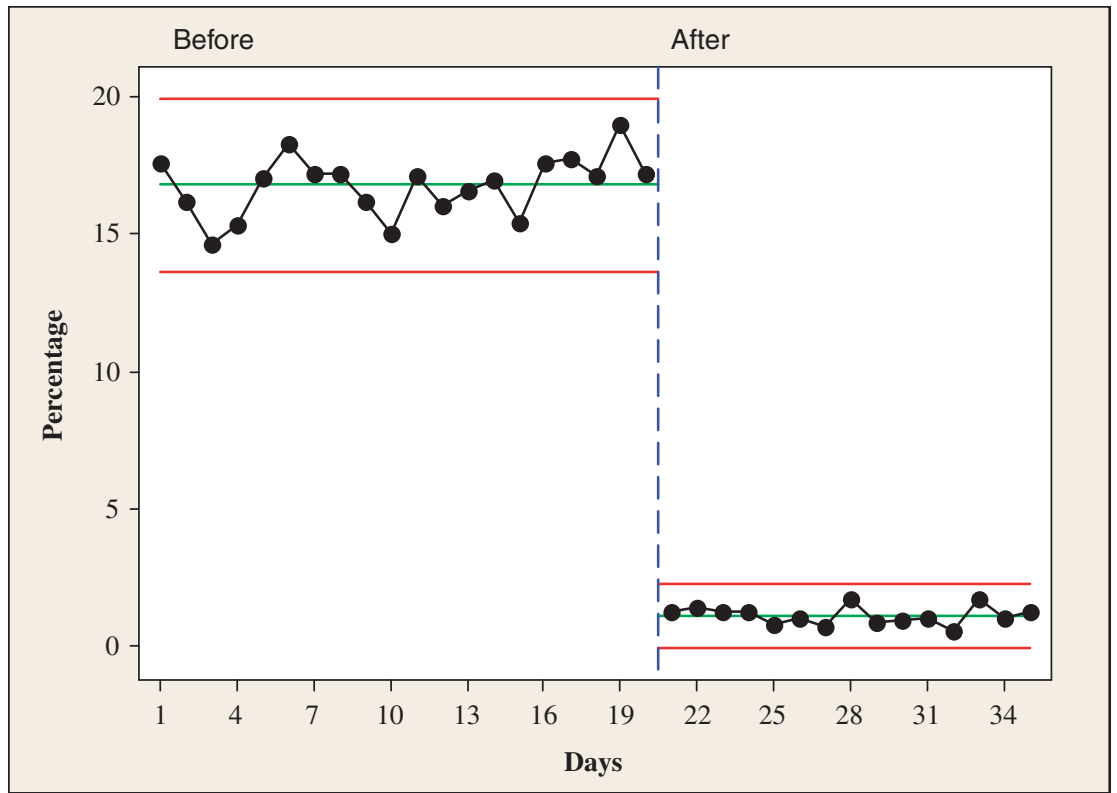

Figure 8. Rejection percentages-before and after the project

implemented and issued to the corresponding users. As a part of ISO 9001 implementation, once in three months internal audits were carried out in the process. The CTQs of the projects were added to the internal audit checklist so that verifications can be performed during the audits. Control chart is a statistical tool used to monitor a process over time to determine whether special causes of variation occur in the process ${ }^{37}$. Implementing appropriate control chart can do future monitoring of the process for assignable causes. Since there was a possibility that different types of defects, such as shades, deep line and patches, can appear after grinding, a control chart needs to be introduced for monitoring the process. Since the defect-related data were collected from the process, the most appropriate control chart for this situation was the $u$ chart ${ }^{37}$. Hence, the $u$ chart was introduced for monitoring the process along with a reaction plan. For every shift, data on number of defects observed during $100 \%$ visual inspection were collected and these values were plotted on the $u$ chart by the quality control inspector attached with this process. When any signal for assignable cause appears in the control chart, the quality control inspector discusses this issue with the operator and immediate action was initiated on the process. The reaction plan displayed near to the machine gives direction for identifying the action required for addressing the assignable cause. Also, training was provided for the people associated with the process about the improved operational methods so that they are able to manage the process effectively.

After implementation, the data were compiled from the fine grinding process with respect to the defects for one month and the rejection percentage was found to be 1.19. Hence, as a result of this project, the rejection percentage of the distance pieces at the fine grinding process reduced from 16.6 to $1.19 \%$. The corresponding approximate sigma level was estimated as 3.76 . Thus, the sigma level of the process has improved from 2.47 to 3.76 . This shows significant improvement in terms of sigma rating as well as defect percentage.

\section{Lessons learned}

Prior to the implementation of Six Sigma, this organization used to practice process improvement methods, such as Statistical Process Control, Quality Circles, Kaizen, 5S, Poka yoke and Shainin techniques ${ }^{38,} 39$. Small issues in various processes were addressed through these approaches. The usage of data and its analysis were mostly absent in this method of improvement practiced in the organization. The success in this Six Sigma case study has given confidence to the people of the organization in data-based decision making. During data analysis, few hidden problems in the process got uncovered. People started understanding the power of statistical thinking and its impact on processes. The learning of statistical software like Minitab has given them opportunity to apply different types of analysis to the collected data and it helped them to come out of the traditional 'experience and intuition' based actions on the process. One critical success factor in the Six Sigma implementation was found to be the management support for the initiative ${ }^{17}$. Because of the management support, the resistance at the operating level in the organization was easily taken care. Otherwise, there used to be initial resistance in terms of providing accurate data from the processes. The systematic usage of statistical techniques in Six Sigma was found to be very powerful in analysing the process data. Also, statistical software was essential for the analysis. However, these packages can be used by people with the correct training. The results obtained by this project will provide start-up data for further implementations in future. We hope that this case will encourage people to use the Six Sigma method to deal with difficult problems, especially where causes are not obvious. 


\section{Managerial implications}

There were isolated efforts in the organization in the past to implement initiatives, such as statistical process control, quality circles, continuous improvement programs, Kaizen, $5 \mathrm{~S}$ and Autonomous maintenance. During the implementation of these initiatives, no systematic effort was made to identify the improvement opportunities in line with business priorities or customer requirements. As a result, the impact of these initiatives was not very visible in the organization whereas in Six Sigma, projects were identified with respect to the voice of the business/customer, and the problems addressed were of highest priority to the organization. Due to success in this project, the management decided to use the Six Sigma methodology for all future improvement initiatives. For monitoring of the Six Sigma initiatives, a core group was formed with all functional heads of the organization. The responsibility of this team was selection of projects and monitoring the execution of projects. All issues related to implementation were also reported to this team for further action. Thus, Six Sigma was introduced as a system in the organization to address any type of problems in the processes. The ultimate objective of the management was to bring a cultural change in the organization by involving everyone in the organization in this movement towards excellence.

\section{Concluding remarks}

The Six Sigma method is a project-driven management approach based on the theories and procedures to reduce the defects for a specified process. This paper presents the step-by-step application of the Six Sigma methodology for reducing the rejection level of the fine grinding process. Several statistical tools and techniques were effectively utilized to make inferences during the project.

As a result of the project, the rejection level of distance pieces after the fine grinding process has been reduced to $1.19 \%$ from $16.6 \%$. Once the results were observed, with the help of the finance department, the team carried out a cost-benefit analysis for the project. Due to improvement in the process, cost associated with rejection, repair, scrap, re-inspection and tool came down drastically. The annualized savings resulted from this project were estimated and found to be about US\$2.4 million. This has given an encouragement for the management to implement the Six Sigma methodology for all improvement initiatives in the organization. Also to encourage the people for participating in the Six Sigma projects, the management declared incentive schemes for the successful teams. In addition to this, during the annual appraisal due weighting was given for individuals who actively participated in the Six Sigma implementation.

Like any other initiative, in Six Sigma also there were inherent difficulties in executing this project. Availability of people for attending training during their busy schedule of day-to-day work was very difficult. Getting support of the people at the lower levels in the organization for participating in the implementation of the solutions was not easy. Since the organization did not have any software for capturing data automatically, collection of data from the process during different phases of the Six Sigma project implementation was also very difficult. The team, by involving people at all levels in the organization, achieved the expected results. Finally, the significant achievement of this project has created many followers for Six Sigma in the organization.

\section{References}

1. Snee RD, Hoerl RW. Leading Six Sigma: A Step by Step Guide Based on Experience at GE and Other Six Sigma Companies. Prentice-Hall: New Jersey, 2003.

2. Kumar M, Antony J, Antony FJ, Madu CN. Winning customer loyalty in an automotive company through Six Sigma: A case study. Quality and Reliability Engineering International 2007; 23(7):849-866.

3. Breyfogle FW. Implementing Six Sigma: Smarter Solutions Using Statistical Methods. Wiley: New York, 1999.

4. Treichler DH. The Six Sigma Path to Leadership. Pearson Education: New Delhi, 2005.

5. Harry M, Schroeder R. Six Sigma: The Breakthrough Management Strategy Revolutionizing the World's Top Corporations. Doubleday: New York, 1999.

6. Park SH. Six Sigma for productivity improvement: Korean business corporations. Productivity Journal 2002; 43:173-183.

7. Pande P, Neuman R, Cavanagh R. The Six Sigma Way: How GE, Motorola and Other Top Companies are Honing their Performance. McGraw-Hill: New York, 2000.

8. Keller PA. Six Sigma Deployment. Quality Publishing House: Arizona, 2001.

9. Gijo EV, Rao TS. Six Sigma implementation-Hurdles and more hurdles. Total Quality Management \& Business Excellence 2005; 16(6):721-725.

10. Pande P, Neuman R, Cavanagh R. The Six Sigma Way Team Field Book: An Implementation Guide for Process Improvement Teams. Tata McGraw-Hill: New Delhi, 2003.

11. Taghizadegan S. Essentials of Lean Six Sigma. Elsevier: New Delhi, 2006.

12. Goh TN. A strategic assessment of Six Sigma. Quality and Reliability Engineering International 2002; 18(5):403-410.

13. Snee RD. Leading business improvement: A new role for statisticians and quality professionals. Quality and Reliability Engineering International 2005; $21(3): 235-242$.

14. Walters L. Six Sigma: Is it really different?. Quality and Reliability Engineering International 2005; 21(3):221-224.

15. Montgomery DC. Generation III Six Sigma. Quality and Reliability Engineering International 2005; 21(6):iii-iv.

16. Brady M, Allen TT. Six Sigma literature: A review and agenda for future research. Quality and Reliability Engineering International 2006; 22(3):335-367.

17. Hahn GJ. Six Sigma: 20 key lessons learned. Quality and Reliability Engineering International 2005; 21(3):225-233.

18. Banuelas R, Antony J, Brace M. An application of Six Sigma to reduce waste. Quality and Reliability Engineering International 2005; 21(6):553-570.

19. Ung ST, Bonsall S, Williams V, Wall A, Wang J. The application of the Six Sigma concept to port security process quality control. Quality and Reliability Engineering International 2007; 23(5):631-639.

20. Aksoy B, Orbak AY. Reducing the quantity of reworked parts in a robotic arc welding process. Quality and Reliability Engineering International 2009; 25(4):495-512. 
21. Gijo EV, Scaria J. Reducing rejection and rework by application of Six Sigma methodology in manufacturing process. International Journal of Six Sigma and Competitive Advantage 2010; 6(1/2):77-90.

22. Lee KL, Wei CC. Reducing mold changing time by implementing Lean Six Sigma. Quality and Reliability Engineering International 2010; 26(4):387-395.

23. Montgomery DC, Runger GC. Applied Statistics and Probability for Engineers (4th edn). Wiley: U.K., 2007.

24. Montgomery DC. Design and Analysis of Experiments (6th edn). Wiley: New York, 2005.

25. Montgomery DC. Introduction to Statistical Quality Control (4th edn). Wiley: New York, 2002.

26. Taguchi G. Systems of Experimental Design, vols 1 and 2. UNIPUB and American Supplier Institute: New York, 1988.

27. Cooper DR, Schindler PS. Business Research Methods. Tata-McGraw Hill: New Delhi, 2006.

28. Bryman A, Bell E. Business Research Methods. Oxford University Press: New Delhi, 2006.

29. Yin RK. Case Study Research: Design and Methods (3rd edn). Sage: California, 2003.

30. Lee TW. Using Qualitative Methods in Organizational Research. Sage: California, 1999.

31. Landis JR, Koch GG. The measurement of observer agreement for categorical data. Biometrics 1977; 33:159-174.

32. Gijo EV. Improving process capability of manufacturing process by application of statistical techniques. Quality Engineering 2005; 17(2):309-315.

33. Gijo EV, Perumallu PK. Quality improvement by reducing variation: A case study. Total Quality Management \& Business Excellence 2003; 14(9):1023-1031.

34. Phadke MS. Quality Engineering using Robust Design. Prentice Hall: Englewood Cliffs, NJ, 1989.

35. Ross PJ. Taguchi Techniques for Quality Engineering. McGraw-Hill: New York, 1996.

36. Wu CFJ, Hamada M. Experiments_Planning, Analysis, and Parameter Design Optimization. Wiley: New York, 2000.

37. Grant EL, Leavenworth RS. Statistical Quality Control (7th edn). Tata McGraw-Hill: New Delhi, 2000.

38. Juran JM, Godfrey AB. Juran's Quality Handbook (5th edn). McGraw-Hill International: New York, 2000.

39. Juran JM, Gryna FM. Quality Planning and Analysis (3rd edn). Tata McGraw-Hill: New Delhi, 1995.

\section{Appendix A: Project Charter}

\begin{tabular}{|c|c|}
\hline \multicolumn{2}{|c|}{ Project Title: Reducing rejection in distance pieces after fine grinding process } \\
\hline \multicolumn{2}{|c|}{$\begin{array}{l}\text { Background and reasons for selecting the project: } \\
\text { The rejection of distance pieces in the fine grinding process was as high as } 16.2 \% \text {. } \\
\text { Approximately } 4200 \text { components are machined during every shift. The cost of } \\
\text { components rejected due to defects was approximately \$US1.6 million per annum. In } \\
\text { addition to this, there was loss associated with tool, machine and man-hour related to } \\
\text { rejection of components. }\end{array}$} \\
\hline \multirow{2}{*}{\multicolumn{2}{|c|}{ Aim of the project: }} \\
\hline & \\
\hline \multirow{2}{*}{\multicolumn{2}{|c|}{$\begin{array}{l}\text { Critical to Quality characteristic: } \\
\text { Rejection percentage of distance pieces after fine grinding process. }\end{array}$}} \\
\hline & \\
\hline Project Scope & Fine grinding process \\
\hline Project Champion: & Head - Manufacturing \\
\hline Project Leader: & Senior Manager - Manufacturing \\
\hline Team Members: & $\begin{array}{l}\text { Planning Manager, Maintenance Manager, } \\
\text { Quality Control Senior Engineer, } \\
\text { Machine Operator. }\end{array}$ \\
\hline Expected Financial Benefits: & $\begin{array}{l}\text { A saving of approximately } \$ \text { US one million in terms of } \\
\text { reduction in rejection and tool cost. }\end{array}$ \\
\hline Expected Intangible Benefits: & $\begin{array}{l}\text { Reduction in rejection will lead to increased output to } \\
\text { meet the market demand and thereby increase in } \\
\text { turnover and reduction in operational expenses. }\end{array}$ \\
\hline Expected customer benefits: & Improving on time delivery. \\
\hline Schedule: & $\begin{array}{l}\text { Define: } 2 \text { Weeks, Measure: } 2 \text { weeks } \\
\text { Analyze: } 3 \text { weeks, Improve: } 4 \text { weeks } \\
\text { Control: } 4 \text { weeks. }\end{array}$ \\
\hline
\end{tabular}




\section{Appendix B: SIPOC}

\begin{tabular}{|c|c|c|c|c|}
\hline Supplier & Input & Process & Output & Customer \\
\hline Supplier & Pre finished parts & \multirow{7}{*}{$\begin{array}{c}\text { Fine Grinding } \\
\text { Process }\end{array}$} & Finished parts & Assembly Shop \\
\hline $\begin{array}{c}\text { Sand Blasting } \\
\text { Process }\end{array}$ & Shot blasted parts & & & \\
\hline Planning & Setting & & \multirow{2}{*}{$\begin{array}{l}\text { Production } \\
\text { Reports }\end{array}$} & \multirow{2}{*}{$\begin{array}{c}\text { Manufacturing } \\
\text { Department }\end{array}$} \\
\hline $\begin{array}{c}\text { Planning } \\
\text { Department }\end{array}$ & Dressing Method & & & \\
\hline $\begin{array}{c}\text { Planning } \\
\text { Department }\end{array}$ & CNC Program & & Quality Reports & $\begin{array}{c}\text { Quality } \\
\text { Department }\end{array}$ \\
\hline $\begin{array}{c}\text { Planning } \\
\text { Department }\end{array}$ & $\begin{array}{l}\text { Visual Limit } \\
\text { Sample }\end{array}$ & & & \\
\hline $\begin{array}{l}\text { Planning } \\
\text { Department }\end{array}$ & Tooling & & & \\
\hline
\end{tabular}

Process Steps

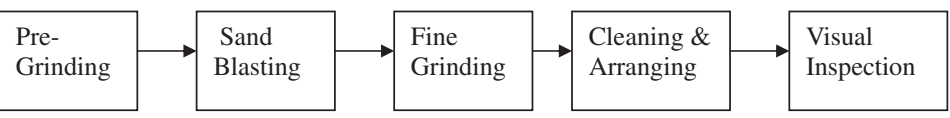

\section{Authors' biographies}

E. V. Gijo is a Faculty at the Statistical Quality Control and Operations Research Unit of Indian Statistical Institute, Bangalore, India. He holds a Master's degree in Statistics from M. G. University, Kottayam, Kerala, and a Master's degree in Quality, Reliability and Operations Research from Indian Statistical Institute, Kolkata. He is an active consultant in the field of Six Sigma, Quality Management, Reliability, Taguchi Methods and allied topics in a variety of industries. He is a certified Master Black Belt and Trainer in Six Sigma and qualified assessor for ISO-9001, ISO-14001 systems. He has published many papers in reputed international journals. He also teaches in the academic programs of the Institute.

Johny Scaria is an Associate Professor in Statistics at Nirmala College, Muvattupuzha, Kerala, India. He holds a Master's Degree and MPhil in Statistics from Kerala University, and PhD in Statistics from Cochin University of Science and Technology. He has published many papers in reputed international journals. He teaches in the academic programmes of the University. His area of interest includes distribution theory, order statistics and statistical quality control. He is an associate editor of the Journal of the Kerala Statistical Association.

Prof. Jiju Antony is Director of the Centre for Research in Six Sigma and Process Improvement (CRISSPE) and Director of Knowledge Exchange within Strathclyde Institute for Operations Management. In his 10 years of research career, he has published more than 200 refereed journal and conference papers and 5 textbooks in the area of Reliability Engineering, Design of Experiments, Taguchi Methods, Six Sigma, Total Quality Management and Statistical Process Control. He has successfully launched the First International Journal of Lean Six Sigma in April 2010. Prof. Antony has been invited several times as a keynote speaker to national conferences on Six Sigma in China, South Africa, Netherlands, India, Greece, New Zealand, South Africa and Poland. Prof. Antony has also chaired the First, Second and Third International Conferences on Six Sigma and First and Second International Workshops on Design for Six Sigma. The recent work of the Prof. Antony includes collaborations with organizations such as Thales Optronics Ltd., Scottish Power, Rolls-Royce, Tata Motors, Bosch, Nokia, GE Domestic Appliances, Scottish Widow, 3M, Land Rover, GE Power Systems, NHS Ayr and Aaran, Kwit Fit Financial Services, Clydesdale Bank, etc. in the development of Six Sigma, Lean and Continuous Improvement programmes within these organizations. He is on the Editorial Board of over eight international journals and a regular reviewer of five leading international journals in quality, operations and production management. He is also the Editor of the International Journal of Lean Six Sigma. 